\title{
Antigenic and genomic characterization of adenovirus associated to respiratory infections in children living in Northeast Brazil
}

\author{
Fernanda EA Moura/ ${ }^{+}$, Jacó RL de Mesquita*, Silvana AR Portes**, \\ Eduardo AG Ramos***, Marilda M Siqueira**
}

\begin{abstract}
Laboratório de Virologia *Programa de Pós-Graduação em Microbiologia Médica, Departamento de Patologia e Medicina Legal, Universidade Federal do Ceará, R. Monsenhor Furtado s/n, 60441-750 Fortaleza, CE, Brasil **Laboratório de Vírus Respiratórios, Instituto Oswaldo Cruz-Fiocruz, Rio de Janeiro, RJ, Brasil ***Laboratório de Patologia, Centro de Pesquisas Gonçalo Moniz-Fiocruz, Salvador, BA, Brasil

From January to December 1998, nasopharyngeal aspirates were obtained from 482 children with acute respiratory infections attended in emergence department and wards of a teaching hospital in the city of Salvador, Brazil. The samples were tested for the presence of adenovirus by isolation in tissue culture and indirect immunofluorescence assay. Eleven adenoviruses were detected by both methods in the same clinical samples. Infections by adenovirus were observed during seven months of the year without association with rainy season. Genome analysis was performed on these 11 isolates. Species $C$ was represented by serotypes 1, 2 and 5. Within species B, only serotype 7 (Ad7) was detected. Two genomic variants of Ad1, two variants of Ad2, one of Ad5, and one of Ad7 (7h) were identified. This is the first study of molecular epidemiology of adenovirus associated to acute respiratory infections in children living in Northeast Brazil, and contributes to a better understanding of adenovirus infections in the country.
\end{abstract}

Key words: adenovirus - acute respiratory infections - genotypes - Brazil

Adenoviruses (Ad) are a significant cause of acute respiratory infections (ARI), including bronchiolitis and pneumonia, in infants and young children. To date 51 human Ad serotypes have been identified, grouped in six species (Ad A to F) based on a variety of parameters, including biochemical, biophysical characteristics and nucleotide, and deduced aminoacid sequences (Wadell 1984, Adrian et al. 1986, van Regenmortel 1999). Ad-B species have been divided further into two subgroups: B1, including Ad type 3 (Ad3), Ad7, Ad16, Ad21 and Ad50, and B2, including Ad11, Ad14, Ad34, and Ad35 (Stone et al. 2003). The serotypes more frequently recovered from children with ARI were: Ad1, Ad2, Ad3, Ad5, and Ad7 (Schimitz et al. 1983). Ad3, Ad7 and, less frequently, Ad 21 , are involved in severe infections in children associated in outbreaks (Kim et al. 2003).

In clinical practice, when the role of Ad is suspected in cases of ARI, the diagnosis is currently based on viral isolation techniques, immunofluorescence and, enzymelinked immunosorbent assays (Vabret et al. 2004). Polymerase chain reaction (PCR), real-time PCR and immunochromatographic kits have recently become available for this purpose (Fujimoto et al. 2004). Typing of Ads isolates can be achieved by neutralization, hemmaglutination inhibition, restriction endonuclease analysis (REA), sequencing and, PCR combined with REA (Allard et al. 2001, Sarantis et al. 2004). Until recently, the interest in serotype and genotype determination of

${ }^{+}$Corresponding author: fernandaedna@terra.com.br Received 10 July 2007

Accepted 12 November 2007
Ad isolates was mainly epidemiological, however, this has changed due to the increasingly clear association between specific serotypes and genotypes and more severe disease presentation (Kajon \& Wadell 1994, Larrañaga et al. 2000, Carballal et al. 2002). Genome typing or REA has been used to ascertain the genetic variation within the species. The identification of genome types offers a chance to follow the epidemiological distribution of these viruses in time and space, and allows their pathogenic and other biological characteristics to be compared.

Several reports of the genomic characterization of Brazilian Ad isolates from patients with respiratory, ocular and gastrointestinal infections have been published since 1988, but none of them included any Ad isolates of patients living in Northeast Brazil (Wadell et al. 1985, Gomes et al. 1988, Moraes et al. 1997, 1998, Kajon et al. 1999, de Albuquerque et al. 2003, Moura et al. 2007). These studies have shown an important genetic variability for members of subgenus C. Among members of subgenus B, serotype 3 has been represented by genotypes $3 \mathrm{p} 1$ and $3 \mathrm{a}$ variant described previously (Kajon et al. 1999, Moura et al. 2007). Data of Brazilian studies suggest replacements of $\mathrm{Ad} 7$ genome types circulating in Brazil as has been reported in other studies (Kajon \& Wadell 1994, Erdman et al. 2000).

The purpose of this study was to describe epidemiological, clinical, and viral characteristics of ARIs by Ad in a group of children attending a teaching hospital in the city of Salvador during the year of 1998.

\section{SUBJECTS, MATERIALS AND METHODS}

Samples of nasopharyngeal aspirates were collected from children presenting upper or lower acute respiratory tract infections who were attending at Centro 
Pediátrico Hosanah de Oliveira (CPHO) in the city of Salvador, northeast Brazil, from January to December 1998. Children under five years of age and with disease of less than seven days of evolution were included in the study. All samples were tested by an indirect immunofluorescence assay (IFA) to Ad, respiratory syncytial virus (RSV), influenza $A$ and $B$, parainfluenzaviruses 1, 2 and 3 (Chemicon International, Temecula, CA, USA) no more than $4 \mathrm{~h}$ after collection. Samples were stored in virus transport medium (Eagle's Minimal Essential Medium with $100 \mathrm{U}$ penicillin and $50 \mathrm{mg}$ gentamicin) and $4 \%$ bovine serum albumin at $-70^{\circ} \mathrm{C}$ until to be inoculated on HEp- 2 cells, when tubes with cells were not available to immediate inoculation. All samples were inoculated on HEp-2 that were grown in Eagle's Minimal Essential Medium containing 10\% of fetal bovine serum, $100 \mu \mathrm{l}$ penicilin and $50 \mu \mathrm{l}$ gentamicin. The cells were observed daily to detect the cytopathic effect (CPE). IFA was performed to confirm the isolation of Ad. Supernatants of culture positive to Ad were stored at $-70^{\circ} \mathrm{C}$. All Ad isolated strains were serotyped by neutralization with rabbit reference antisera for Ad types 1, $2,3,4,5,6$, and 7 , following standard protocols (Hierholtzer 1995). HEp-2 cells grown in $75 \mathrm{~cm}^{2}$ plastic flasks were inoculated with Ad that were stored at $-70^{\circ} \mathrm{C}$. Viral DNAs were extracted from infected cells as described previously (Shinagawa et al. 1983). Aliquots containing 1-2 $\mu \mathrm{g}$ of viral DNAs were digested with 10 units of different endonucleases (Bam HI, Bgl II, BstE II, Hind III, and Sma I) under conditions specified by the manufacturers (Boehringer, Mannheim, Germany). DNA fragments were loaded onto $1.2 \%$ agarose gels. Bands were observed by using a transilluminator, and photographed using Polaroid Land film 665 or 667 . The resulting restriction profiles were assigned to corresponding virus species and genotypes according to the literature data.

Ethical issues - This study was approved by Ethics Committee of CPHO (resolution 14/97). Parents or legal guardians provided signed informed consents for inclusion of children in the study.

\section{RESULTS}

From January to December 1998, 482 samples were collected, 360 from patients attending the emergency department and 122 from hospitalized patients. Viral infections were detected in 154 patients. Adenoviral infections (11 cases) represented $7.14 \%$ of viral infections, and $2.28 \%$ of all cases of ARI. Ads were the fourth viral agent after RSV, influenza A and parainfluenza 3. In this study, Ad infections were more prevalent in the children attending the emergence than in those being treated at wards. Adenoviral infections were observed in children aged two months to four years with most of them occurred during the first year of their lives (81.8\%). The majority of infections caused by Ad (63.6\%) were diagnosed as upper respiratory tract infections (URTI). Cases of lower respiratory tract infections (LRTI) were observed in outpatients and those hospitalized. Characteristics of the children with ARI caused by Ad are shown in Table. All of the 11 Ad detected by IFA were isolated in HEp-2 cells.

The genomic analysis showed that $83.3 \%$ of the analyzed isolates belonged to the species $\mathrm{C}$, and was represented by serotypes 1, 2 and 5 followed by species represented by serotype 7 accounting for $16.7 \%$ of the cases. The seroneutralization test identified four Ad1, two Ad2, one Ad5 and four Ad7. The restriction profiles of adenoviruses analysed in this study are shown in Figs 1 and 2. Two DNA variants were observed among strains classified as Ad1, one was identified as genome type D1 and three as D10 (only two of them are showed in the Fig. 2). Strains of Ad2 were characterized as genome type D5. The only Ad5 of this study had a similar pattern to that named as $5 \#$ in an Argentine study (Kajon \& Wadell 1992). All four Ad7 identified were characterized as $7 \mathrm{~h}$.

\section{DISCUSSION}

In this study Ad infections were more prevalent in the children who were attended in the emergency department than those attended in the wards. This finding differs from data reported by other Brazilian and South

TABLE

Adenovirus strains isolated from nasopharyngeal aspirates of children with acute respiratory disease in Salvador, Brazil, from January to December 1998

\begin{tabular}{rccccc}
\hline Strain & Gender & Age (months) & Setting of attending & Diagnostic & Serotype \\
\hline $82 / 98$ & Male & $20 \mathrm{~m}$ & ED & Tonsilitis & Ad1 \\
$151 / 98$ & Male & $9 \mathrm{~m}$ & W & Bronchiolitis & Ad7 \\
$236 / 98$ & Female & $12 \mathrm{~m}$ & ED & Bronchiolitis & Ad2 \\
$260 / 98$ & Female & $48 \mathrm{~m}$ & ED & Tonsillitis & Ad1 \\
$261 / 98$ & Male & $12 \mathrm{~m}$ & ED & Bronchiolitis + Pneumonia & Ad7 \\
$275 / 98$ & Male & $11 \mathrm{~m}$ & FD & Tonsilitis & Ad7 \\
$325 / 98$ & Female & $36 \mathrm{~m}$ & ED & FURTI & Ad7 \\
$381 / 98$ & Male & $12 \mathrm{~m}$ & W & Bronchiolitis + Pneumonia & Ad1 \\
$386 / 98$ & Female & $8 \mathrm{~m}$ & ED & FURTI & Ad1 \\
$427 / 98$ & Male & $10 \mathrm{~m}$ & ED & FURTI & Ad2 \\
$466 / 98$ & Male & $4 \mathrm{~m}$ & & &
\end{tabular}

ED: emergency department; W: ward; FURTI: febrile upper respiratory tract illness. 


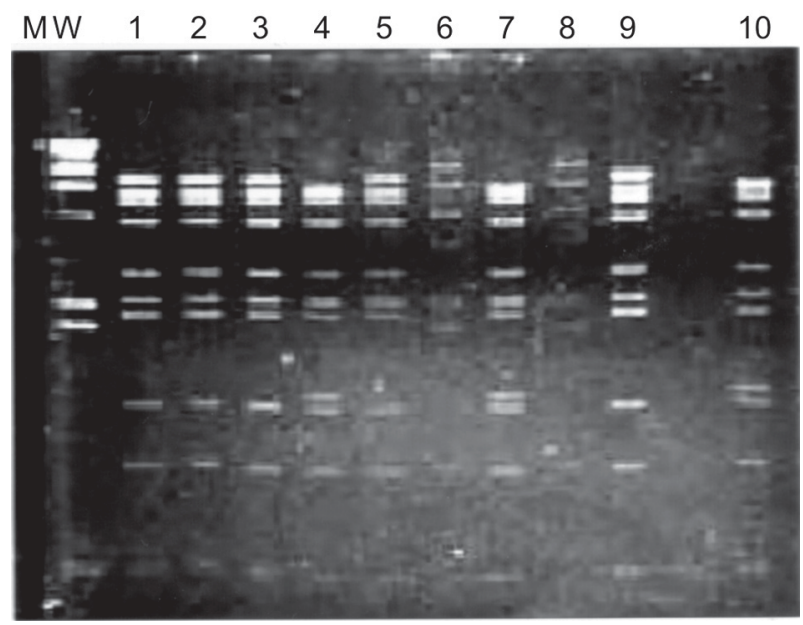

Fig. 1: restriction profiles of adenoviruses isolated after digestion with $\mathrm{Sma}$ I. MW: molecular weight marker. Lines - 1, 2, 3, 5, and 9 (Ad2); Lines - 4, 7, and 10 (Ad1); Lines - 6 and 8 (Ad7).

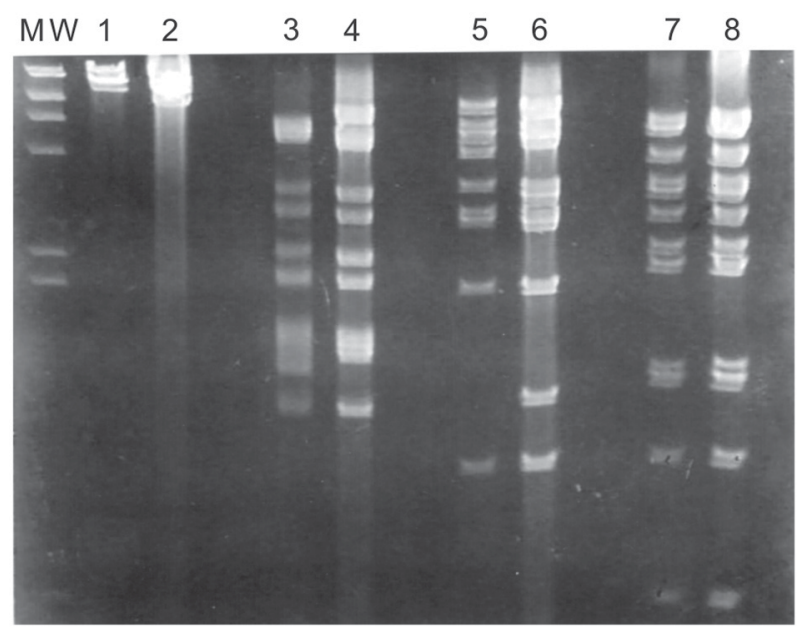

Fig. 2: restriction profiles of only adenovirus 5 isolated. MW: molecular weight marker. Lines - 1, 3, 5, and 7 (Ad prototype 5 after digestion with Bam HI, Bgl II, Hind III e SmaI, respectively); Lines - 2, 4, 6, and 8 (Ad type 5 isolated in the study after digestion with Bam HI, Bgl II, Hind III e SmaI, respectively).

American studies, which indicate Ad as the second most prevalent virus in ARI observed in hospitalized children (Nascimento et al. 1991, Kajon et al. 1999, Larrañaga et al. 2000, Straliotto et al. 2002). In this study the rate of ARI by Ad in hospitalized patients was $1.6 \%$, while in other studies this rate ranged from $3.3 \%$ to $12.6 \%$ (Larrañaga et al. 2000, Hong et al. 2001, Tsai et al. 2001, Chen et al. 2004). Respiratory infections by Ad are generally characterized as self-limited mild URTI, however LRTI can occur, and some cases present as severe pneumonia followed by respiratory failure, serious sequelae or fatal outcome (Kajon \& Wadell 1994, Farng et al. 2002). In other similar studies, Ad was seen to act as an agent of URTI (Tsai et al. 2001, Echavarria et al. 2006). In a recent study, Ad was detected in $9.4 \%$ of nasal swab samples collected from outpatients with flu-like symptoms (Echavarria et al. 2006). The impact and severity of Ad infections were shown in a study of viral acute lower tract infections in children admitted to the pediatric intensive care unit of two hospitals in the city of Porto Alegre (Straliotto et al. 2004). In that study, $7.7 \%$ of viral respiratory infections were due to Ad. Moreover those infections showed a high case fatality rate of $25 \%$.

During the twelve months of study, Ad infections were observed year round without a clear seasonality as it was observed in other Brazilian cities and in other tropical countries (Arruda et al. 1991, Nascimento et al. 1991, Shek \& Lee 2003, Tsuchiya et al. 2005).

Referring to the antigenic diversity of Ad associated to children ARI in Salvador in 1998 it was observed that members of species $C$ predominated, in accordance with other studies (Frabasile et al. 2005, Echavarria et al. 2006). This characteristic differs from those seen in studies in Argentina and Chile, where members of species B were the most prevalent (Kajon et al. 1996, Videla et al. 1998, Larrañaga et al. 2000, Carballal et al. 2002).

In spite of the small number of Ad analyzed, the results of this study show a relative genetic variability for members of species C, as observed previously (Kajon et al. 1999, Frabasile et al. 2005, Moura et al. 2007). Several studies have shown that one particular genotype can circulate in different geographic regions in different years. The data obtained in this study show that genotypes circulating in Salvador during 1998 had circulated in other Brazilian cities and other South American countries in previous years. The genotypes D1 and D10 of Ad1, and the genotype D5 of Ad2 identified in Salvador during 1998 had circulated in the cities of Belém and Rio de Janeiro in the 80s and early 90s (Kajon et al. 1999). The only Ad5 detected in Salvador had circulated in Argentina between 1984 and 1988 (Kajon \& Wadell 1992).

The finding of four Ad of genotype $7 \mathrm{~h}$ in Salvador in 1998 confirms the tendency of this genotype to spread rapidly, since it was first identified in Argentina (Kajon \& Wadell 1994). The occurrence of this genome type remained restricted in countries of South Cone of South America (Argentina, Chile and Uruguay) until 1994, when it was identified in Southeast Brazil associated to a case of follicular conjunctivitis (Tanaka et al. 2000). The circulation of this genome type outside of South America occurred in 1996 in Japan and in 1998 in Southeast of United States (Hashido et al. 1999, Erdman et al. 2000). The first identification of Ad7h in case of ARI in Brazil occurred in 1995 (Moura et al. 2007). Previous analysis of Ad7 in Brazil had identified only the genome types Ad7b and Ad7e (Wadell et al. 1985, Moraes et al. 1997, Kajon et al. 1999). The analysis of 40 strains of Ad7 identified in cases of ARI in patients living in Southern and Southeastern regions of Brazil showed that in a period of 12 years (1980-1991) only the genome types Ad7b and Ad7e were identified (Moraes et al. 1997). Similar result was observed among 14 strains of Ad7 isolated from respiratory specimens from patients with ARI 
living in Northern and Southeastern regions between 1976 and 1995 (Kajon et al. 1999). In the more recent Brazilian study about molecular epidemiology of adenovirus revealed that all 17 serotype isolates belonged to genome type 7h (Moura et al. 2007). Shifts or replacements of genome types of $\mathrm{Ad} 7 \mathrm{had}$ been reported in the former Soviet Union, Argentina and Australia (Li \& Wadell 1986, Galovina et al. 1991, Kajon \& Wadell 1994). More continuous studies with a larger number of strains in analysis are required in order to characterize if in Brazil the genome types Ad7b and Ad7e were replaced by Ad7h as has been suggested in the Brazilian studies cited previously.

The principal limitations of this study are related to the low number of strains analyzed and the long time past since the circulation of them. These strains of Ad represented the only isolated from respiratory specimens of children living in Northeast Brazil available for study, and contribute for a better understanding of Ad in the country. The comparison of the results of the present study with those presented in Brazilian studies published before and after 1998 allows us to observe that the circulation of some genotypes of adenovirus detected in Salvador had been reported before of the present study, and they remained circulating in Brazil years after. At same time, this study confirms the quick spread of Ad7h in South America. This is the first report about molecular epidemiology of adenovirus circulating in Northeast Brazil.

\section{REFERENCES}

Adrian T, Wadell G, Hierholtzer JC, Wigand R 1986. DNA restriction analysis of adenovirus prototype 1 to 41 . Arch Virol 91: 277-290.

Allard A, Albinsson B, Wadell G 2001. Rapid typing of human adenoviruses by a general PCR combined with restriction endonuclease analysis. J Clin Microbiol 39: 498-505.

Arruda E, Hayden FG, McAuliffe JF, de Sousa MA, Mota SB, McAuliffe MI, Geist FC, Carvalho EP, Fernandez MC, Guerrant RL, Gwaltney JM 1991. Acute respiratory viral infections in ambulatory children of urban northeast Brazil. $J$ Infec Dis 164: 252-258.

Carballal G, Videla C, Misirlian A, Requeijo PV, Aguilar MC 2002. Adenovirus type 7 associated with severe and fatal acute lower respiratory infections in Argentine children. $B M C$ Pediatr 16: 2-6.

Chen HL, Chiou SS, Hsiao HP, Ke GM, Lin YC, Lin KH, Jong YJ 2004. Respiratory adenoviral infections in children: a study of hospitalized cases in Southern Taiwan in 2001-2002. J Trop Pediatr 50: 279-284.

de Albuquerque MC, da Silva FM, Soares CC, Volotão EM, Santos N 2003. Adenoviruses isolated from civilian and military personnel in the city of Rio de Janeiro, Brazil. Rev Inst Med Trop São Paulo 45: 233-236.

Echavarria M, Maldonado D, Elbert G, Videla C, Rappaport P, Carballal G 2006. Use of PCR to demonstrate presence of adenovirus species $\mathrm{B}, \mathrm{C}$, or $\mathrm{F}$ as well as coinfection with two adenovirus species in children with flu-Like symptoms. JClin Microbiol 44: 625-627.

Erdman DD, Xu W, Gerber SI, Gray GC, Schnurr D, Kajon A, Anderson LJ 2000. Molecular epidemiology of adenovirus type 7 in the United States, 1966-2000. Emer Infect Dis 8: 269-277.

Farng KT, Wu KG, Lee YS, Lin YH, Hwang BT 2002. Comparison of clinical characteristics of adenovirus and non-adenovirus pneumonia in children. J Microbiol Immunol Infect 35: $37-41$.

Frabasile S, Vitureira N, Perez G, Mateos S, Arbiza J 2005. Genotyping of Uruguayan human adenovirus isolates collected between 1994 and 1998. Acta Virologica 49: 129-132.

Fujimoto T, Okafuji T, Okafuji T, Mashiro I, Nukuzuma S, Chikarira M, Nishio O 2004. Evaluation of a bedside immunochromatographic test for detection of adenovirus in respiratory samples, by comparison to virus isolation, PCR, and realtime PCR. J Clin Microbiol 42: 5489-5492.

Galovina GI, Zolotaryov FN, Yurlova TI 1991. Sensitive analysis of genetic of genetic heterogeneity of adenovirus 3 and 7 in the Soviet Union. J Clin Microbiol 29: 2313-2121.

Gomes SA, Gabbay YB, Nascimento JP, Niel C 1988. Genome analysis of adenovirus $4 \mathrm{a}$, a causative agent of pharyngoconjunctival fever and respiratory diseases in Brazil. JMed Virol 26: 453-459.

Hashido M, Mukouyama A, Sakae K, Tsuzuki H, Yamashita T, Inada T, Inouye S 1999. Molecular and serological characterization of adenovirus genome type $7 \mathrm{~h}$ isolated in Japan. Epidemiol Infect 122: 281-286.

Hierholtzer JC 1995. Adenoviruses. In EH Lennette, DA Lennette, ET Lennette (eds), Diagnostic Procedures for Viral, Rickettsial and Chlamydial Infections, Am Publ Health Assoc, Washington, DC, p.169-188.

Hong JY, Lee HJ, Piedra PA, Choi EH, Park KH, Koh YY, Kim WS 2001. Lower respiratory tract infections due to adenovirus in hospitalized Korean children: epidemiology, clinical features and prognosis. Clin Infect Dis 32: 1423-1429.

Kajon AE, Mistchenko AS, Videla C, Hortal M, Wadell G, Avendaño LF 1996. Molecular epidemiology of adenovirus acute lower respiratory infections of children in the south cone of South America (1991-1994). J Med Virol 48: 151-156.

Kajon AE, Portes SA, Mello WA, Nascimento JP, Siqueira MM 1999. Genome type analysis of Brazilian adenovirus strains of serotypes 1, 2, 3, 5 and 7 collected between 1976 and 1995. J Med Virol 58: 408-412.

Kajon AE, Wadell G 1992. Molecular epidemiology of adenoviruses associated with acute lower respiratory disease of children in Buenos Aires, Argentina (1984-1988). J Med Virol 36: 292-297.

Kajon A, Wadell G 1994. Genome analysis of South American adenovirus strains of serotype 7 collected over a 7-year period. J Clin Microbiol 32: 2321-2323.

Kim YJ, Hong JY, Lee HJ, Shin SH, Kim YK, Inada T, Hashido M, Piedra PA 2003. Genome type analysis of adenovirus types 3 and 7 isolated during successive outbreaks of lower respiratory tract infections in children. J Clin Microbiol 41: 4594-4599.

Larrañaga C, Kajon A, Villagra E, Avendano LF 2000. Adenovirus surveillance on children hospitalized for acute lower respiratory infections in Chile (1988-1996). JMed Virol 60: 342-346.

Li QG, Wadell G 1986. Analysis of 15 different genome types of adenovirus type 7 isolated in five continents. $J$ Virol 60 : 331-335. 
Moraes MT, da Silva M, Leite JP, Nascimento JP 1998. Genetic and antigenic analysis of adenovirus type 3 strains showing intermediate behavior in standard seroneutralization test. Mem Inst Oswaldo Cruz 93: 231-235.

Moraes MT, Leite JP, Siqueira MM, Portes SA, Krawczuc MM, Nascimento JP 1997 Genomic characterization of adenovirus serotype 7 isolated in Brazil from acute respiratory disease patients during the period from 1980 to 1991 . Rev Inst Med Trop São Paulo 39: 185-189.

Moura PO, Roberto AF, Hein N, Baldacci E, Vieira SE, Ejzemberg B, Perrini P, Stewien KE, Durigon EL, Mehnert DV, Harsi CM 2007. Molecular epidemiology of human adenovirus isolated from children hospitalized with acute respiratory infection in São Paulo, Brazil. J Med Virol 79: 174-181.

Nascimento JP, Siqueira MM, Sutmoller F, Krawczuk, MM, Farias V, Ferreira V, Rodrigues MJ 1991. Longitudinal study of acute respiratory diseases in Rio de Janeiro: occurrence of respiratory viruses during four consecutive years. Rev Inst Med Trop São Paulo 33: 287-296.

Sarantis H, Johnson G, Brown M, Martin Petric, Raymond T 2004. Comprehensive detection and serotyping of human adenoviruses by PCR and sequencing. J Clin Microbiol 42: 3963-3969.

Shek LPC, Lee BW 2003. Epidemiology and seasonality of respiratory tract virus infections in the tropics. Paediatr Respir Rev 4: 105-111.

Shimitz H, Wigand R, Heinrich W 1983. Worldwide epidemiology of human adenovirus infections. Am J Epidemiol 117: 455-466.

Shinagawa M, Matsuda A, Ishiyama T, Goth H, Sato G 1983. A rapid and simple method for preparation of adenovirus DNA from infected cells. Microbiol Immunol 27: 817-822.

Stone D, Furthmann A, Sandig V, Lieber A 2003. The complete nucleotide sequence, genome organization, and origin of human adenovirus type 11. Virology 309: 152-65.

Straliotto SM, Siqueira MM, Machado V, Maria TMR 2004. Respiratory viruses in the pediatric intensive care unit: prevalence and clinical aspects. Mem Inst Oswaldo Cruz 99: 883-887.

Straliotto SM, Siqueira MM, Muller RL, Fischer GB, Cunha MLT, Nestor SM 2002. Viral etiology of acute respiratory infec- tions among children in Porto Alegre, RS, Brazil. Rev Soc Bras Med Trop 35: 283-291.

Tanaka K, Itoh N, Saitoh-Inagawa W, Saitoh-Inagawa W, Uchio E, Takeuchi S, Aoki K, Soriano E, Nishi M, Junior RB, Harsi CM, Tsuzuki-Wang L, Durigon EL, Stewien KE, Ohno S 2000. Genetic characterization of adenovirus strains isolated from patients with acute conjunctivitis in the city of São Paulo, Brazil. J Med Virol 61:143-149.

Tsai HP, Kuo PH, Liu CC, Wang JR 2001. Respiratory viral infections among pediatric inpatients and outpatients in Taiwan from 1997 to 1999. J Clin Microbiol 39: 111-118.

Tsuchiya LR, Costa LM, Raboni SM, Nogueira MB, Pereira LA, Rotta I, Takahashi GRA, Coelho M, Siqueira MM 2005. Viral respiratory infections in Curitiba, Southern Brazil. J Infect 51: 401-407.

Vabret A, Gouarin S, Joannes M, Barrenger C, Petitjean J, Cobert S, Brouard J, Lafay F, Duhanmel JF, Guillois B, Freymuth F 2004. Development of a PCR and hybridization-based assay (PCR Adenovirus Consensus) for the detection and the species identification of adenoviruses in respiratory specimens. $J$ Clin Virol 31: 116-122.

van Regenmortel MHV, Fauquet CM, Bishop DHL, Carstens EB, Mayo MA, McGeoch DJ 1999. Family Adenoviridae. In MHV van Regenmortel, CM Fauquet, DHL Bishop, EB Carstens, MK Estes, SM Lemon, J Maniloff, MA Mayo, DJ McGeoch, CR Pringle, EB Wickner, Virus Taxonomy: Classification and Nomenclature of Viruses, Academic Press, San Diego, p. 227-237.

Videla, C, Carballal G, Misirlian A, Aguilar M 1998. Acute lower respiratory infections due to respiratory syncytial virus and adenovirus among hospitalized children from Argentina. Clin Diagn Virol 10: 17-23.

Wadell G 1984. Molecular epidemiology of human adenoviruses. Curr Top Microbiol Immunol 110: 191-220.

Wadell G, Cooney MN, Linhares AC, Silva L, Kennett ML, Kono R, Gui-Fung R, Lindman K, Nascimento JP, Shoub BD, Smith CD 1985. Molecular epidemiology of adenovirus: global distribution of adenovirus 7 genomes types. J Clin Microbiol 21:403-408. 
